\title{
Computational Solution of Two- Point Boundary Value Problem by Quadrature method in terms of Liouville-Green Transformation
}

\author{
Ch.Baby Rani, J. Venkata Brahman, K. Sharath Babu
}

\begin{abstract}
In this research paper we are selected a two-pointedge value problem of singular perturbation with Dirichlet type of margin conditions. The selected differential equation is transformedinto to the required form by using a Liouville -Green transformation. Then the computational process has been implemented for solving thetwo-pointborder line value problem ofsingular perturbation with either right or left end frontier layer in the specific interval [0,1]. The transformation reduces the mathematical complexity with some assumptions and applied numerical integration method to get the computations for different choices of the perturbation parameter, which is very near to zero. In the present research problem, we have observed the uniform convergence in the computational solution in the regular region and some chaotic behavior near the periphery layer region. We are implemented this method for several linear differential equations and observed that the numerically obtained resultsare validated with literature.
\end{abstract}

KEYWORDS: Singular Perturbation, Perturbation parameter, Quadrature,state line narrowregion, Liouville-Green Transform, numerical solution.

\section{INTRODUCTION}

Differential equations occur quiteoften in the mathematical modeling of physical problems in various disciplines of science, technology and engineering. Since exact solutions for most of these problems are not available, a resort to the approximation methods for getting the solution of such problems is unavoidable. The availability of the high-speed digital computers has made it possible to take such a task when the approximation method involves numerical computation using FDM AND FEM methods. The problems of singular perturbation have found solutions very frequentlyin the great world of Fluid mechanics,Fluid dynamics, Chemical engineering, Boundary layer phenomenon, reaction-diffusion processes, Aerodynamics and Geophysics.

Two-point boundary singularly perturbation possess the boundary layers and/or interior layers (at which the solution become more rapidoneither end points or a few inner points with width $O$ (1) as $\varepsilon \rightarrow \rightarrow 0$ ). Recently, the researchers have proposedvariety of special methods for providing the most plausible solution i.e as near as to the exact solutions using

Revised Manuscript Received on September 15, 2019.

Dr. Ch.Baby Rani: Dept. of Mathematics, V.R. Siddhartha Engg.College Vijayawada, Krishna District, AP, India.

J. Venkata Brahman: Research Scholar, Krishna University, Machalipatnam, Krishna District, AP, India.

Dr. K. Sharath Babu: Faculty of Mathematics, Matrusri Engineering college, Saidabad, Hyderabad. numerical solutions. Among them, one particular method is there to divide the interval into small meshes with equal or unequal width by solving asymptotic expansions of the inner and outer regions such that the constants can be determinedby giving a uniform valid solution. Usually, the problems of inner region can be obtained by considering the actual problem with the help of scale change in independent variables. Such type ofmethodologies and their modificationshave been applied successfully for the solution of enormous linear and nonlinearproblems of singular perturbation..Of course, triumphof validation of the technique depends on setting up appropriate scaling and/or transformation to state dependent as well as independent variables.

The excellent article given by J. Kevorkian, J.D. Cole [5] resultsthe scholarlyoutcome of solution for theproblemswith singular perturbation; and their solution methodology starting from Prandtl's paper [9] onproblem of boundary layers in fluid dynamics.

Further, one can refer the theory and analysis of singular perturbation problems in the literature:A.M. Il'in [1], Bender and Orszag [2], L.E.EL'sgol'tsetal. [3], P.W. Hemkeretal. [4]. Kevorkian and Cole [5], Nayfeh [6], and O'Malley [7, 8].

In the present study, singularly perturbed two-point boundary second orderproblem with right end boundary layer using Liouville-Green transform\& numerical quadrature;and we have obtained asymptotic and computational solutions. We have demonstrated some illustrations for validity of this method.

\section{LIOUVILLE-GREEN TRANSFORMS}

Let us converse presentprocess (proposal) for exceptionally perturbed two - point limit value problems with right -end boundary narrow region of the principalinterval.Particularly, we have defined a course group of outstanding perturbation difficulty of the non-homogeneous form as follows:

$\varepsilon y^{n s}-f(x) y^{s}(x)-g(x) y(x)=h(x), x \in[0,1]$

With the boundary conditions

$$
\mathrm{y}(0)={ }^{\alpha} \text { and } \mathrm{y}(1)={ }^{\beta}
$$

Where $\varepsilon^{\varepsilon_{i}}$ very small $(0<\varepsilon<1) ; \alpha{ }_{o} \beta$ are known values of constants;And $\mathrm{f}(\mathrm{x}), \mathrm{g}(\mathrm{x})$ are continuously differentiable functions in the interval $[0,1]$. The coefficient of $y^{b}(x)$ is depressing and non- zero inthe interval $[0,1]$. 
$-\varepsilon y^{\prime \prime}+f(x) y^{\prime}(x)+g(x) y(x)=h(x), x$ is a point in the closed intervel [01] 03

Let us consider the Lowville -Green transforms with usual functions $\mathrm{z}, \varphi(x), \mathrm{v}(\mathrm{z})$ be

$$
\begin{aligned}
& \mathrm{Z}=\varphi(x)=\frac{1}{s} \int f(x) d x \\
& \Phi(x)=\varphi^{s}(\mathrm{x})=\frac{\mathbb{1}}{8} f(x)
\end{aligned}
$$

In equation (4) the integral can be evaluating by using numerical quadrature method.

\section{EVALUATION OF THE NUMERICAL INTEGRAL:}

In equation (4) Select the starting point as $\mathrm{x} 0$ and the terminal point as $x i+1$ and divide the interval in to subintervals such that in each subinterval the total number of entry values are multiples of 2 . Now applying the Simpson $1 / 3$ rd rule in each subinterval in $[0,1]$ we have

$$
\begin{aligned}
& \int_{x_{i}-1}^{x_{i}+1} f(x) d x= \\
& y_{i+1}-y_{i-1}=\frac{h}{3}\left[p_{i+1}\left[\left(1-\frac{\delta}{h}\right) y_{i+1}+\frac{\delta}{h} y_{i}\right]+4 p_{i}\left[y_{i}-\frac{\delta}{2 h}\right.\right. \\
& +\left(p_{i+1}+p_{i-1}\right)\left[\left(1-\frac{\delta}{h}\right) y_{i+1}+\frac{\delta}{h} y_{i}+\left(1+\frac{\delta}{h}\right) y_{i-1}-\frac{\delta}{h} y_{i}+\right. \\
& \text { Where } \\
& p(x)=\frac{-2 \varepsilon}{2 \delta \varepsilon+\delta^{2} \mathrm{f}(\mathrm{x})} \\
& \mathrm{q}(\mathrm{x})=\frac{2 \varepsilon-\delta^{2} \mathrm{~b}(\mathrm{x})}{2 \varepsilon \delta+\delta^{2} \mathrm{f}(\mathrm{x})}
\end{aligned}
$$$$
+\left(\mathrm{p}_{\mathrm{i}+1}+\mathrm{p}_{\mathrm{i}-1}\right)\left[\left(1-\frac{\delta}{\mathrm{h}}\right) \mathrm{y}_{\mathrm{i}+1}+\frac{\delta}{\mathrm{h}} \mathrm{y}_{\mathrm{i}}+\left(1+\frac{\delta}{\mathrm{h}}\right) \mathrm{y}_{\mathrm{i}-1}-\frac{\delta}{\mathrm{h}} \mathrm{y}_{\mathrm{i}}+2 \mathrm{q}_{\mathrm{i}+1} \mathrm{y}_{\mathrm{i}+1}+2 \mathrm{q}_{\mathrm{i}-1} \mathrm{y}_{\mathrm{i}-1}+4 \mathrm{q}_{\mathrm{i}} \mathrm{y}_{\mathrm{i}}+2 \mathrm{r}_{\mathrm{i}+1}+\underset{\mathrm{v}(\mathrm{z})}{4 \mathrm{r}_{\mathrm{i}}} \approx_{\mathrm{C}_{1}}+2 \mathrm{r}_{\mathrm{i}+1} \mathrm{C}_{2} \mathrm{e}^{\mathrm{z}}\right.
$$

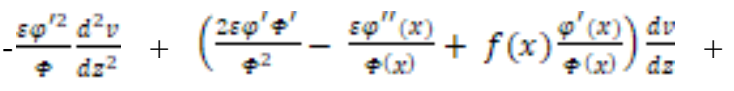

$$
\begin{aligned}
& \left(\frac{\varepsilon \Phi^{g}(x)}{\Phi^{2}(x)}-\frac{2 \varepsilon \Phi^{\prime 2}(x)}{\Phi^{3}(x)}-f(x) \frac{\Phi^{y}(x)}{\Phi^{2}}+\frac{g(x)}{\varphi}\right) \quad \mathrm{v}(\mathrm{z}) \\
& =\mathrm{h}(\mathrm{x})
\end{aligned}
$$

i.e.

$$
\begin{aligned}
& \frac{d^{2} V}{d z^{2}}-\frac{d V}{d z}=\varepsilon \frac{f^{y}(x)}{f^{2}(x)} \frac{d V}{d z}+\varepsilon \frac{1}{f^{2}(x)}\left(\varepsilon \frac{f^{n v}(x)}{f(x)}-2 \varepsilon \frac{f^{p}(x)}{f^{2}(x)}-\right. \\
& \left.f^{v}(x)+g(x)\right) \\
& \mathrm{v}(\mathrm{z})=F(x) \frac{d v}{d z}+\varepsilon G\left(\varepsilon_{x} x\right)_{V}(z)_{x}(12)
\end{aligned}
$$

Where $\mathrm{F}(\mathrm{x})=\frac{f^{\prime}(x)}{f^{2}(x)} \quad, \mathrm{G}(\mathrm{x}, \quad$ ह) $=$ $\frac{1}{f^{2}(x)}\left(\varepsilon \frac{f^{n(y)}}{f^{(x)}}-2 \varepsilon \frac{f^{n}(x)}{f^{2}(x)}-f^{\prime}(x)+g(x)\right)$

Since $\varepsilon$ is a very $\operatorname{small}(0<<\varepsilon<1), \varepsilon F(x)$ and ${ }^{\varepsilon} \mathrm{G}\left(\mathrm{x},{ }^{\varepsilon}\right)$ are suitably small in $[0,1]$.So,as $\varepsilon \rightarrow \rightarrow 0$, the right offer side of Equation(9) not vanishes but close to zero.

Therefore, we have an assumed approximation

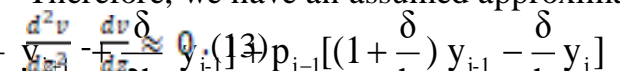

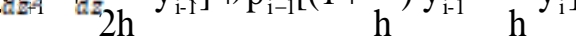

everywhere, $\mathrm{C}_{1}$ and $\mathrm{C}_{2}$ are theuninformed constants. From (4) -(6), we can obtain the asymptotic(6solutions of discrepancy equations

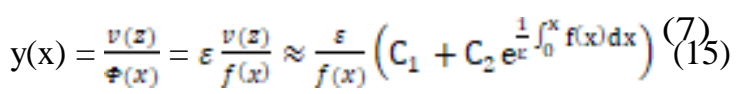

where $\mathrm{C}_{1}, \mathrm{C}_{2}$ are two arbitrary constants.

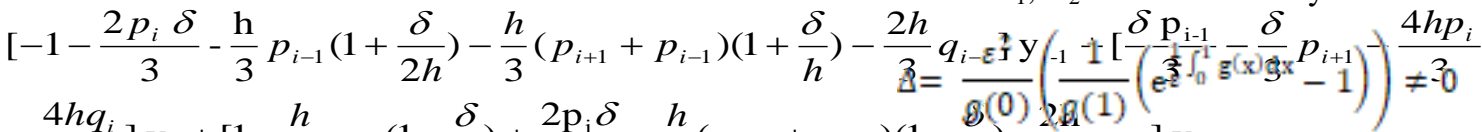

$$
\begin{aligned}
& \left.-\frac{4 h q_{i}}{3}\right] \mathrm{y}_{\mathrm{i}}+\left[1-\frac{h}{3} p_{i+1}\left(1-\frac{\delta}{h}\right)+\frac{2 \mathrm{p}_{\mathrm{i}} \delta}{3}-\frac{h}{3}\left(p_{i+1}+p_{i-1}\right)\left(1-\frac{g}{h}\right)-\frac{2 \mathrm{~g}(1)}{3} q_{i+1}\right] \mathrm{y}_{\mathrm{i}+1}
\end{aligned}
$$

$$
=\frac{2 \mathrm{~h}}{3}\left[r_{i+1}+2 r_{i}+r_{i-1}\right] \quad \text { integration method mentioned in Equation (8) }
$$

Then the above TwoPointBoundary value problem (13)

After perforating the interval integration in each sub-interval with the uniform step width select the transformation.

$\mathrm{v}(\mathrm{z})=\mathrm{y}(\mathrm{x}) \Phi(\mathrm{x})$

According to (9), with the usual calculus weobtain

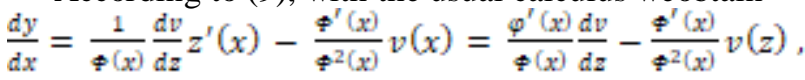

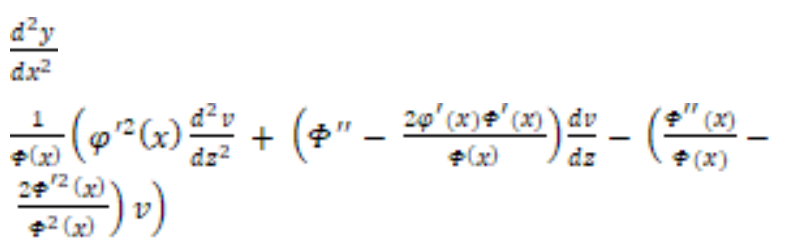

(11)

From (3), (9) (10) \& (11), and we can obtain possesses the following asymptotic solution:

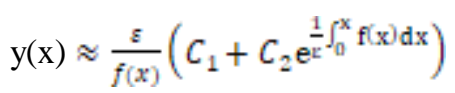

Where $_{1}, \mathrm{C}_{2}$ can be evaluated. With the specified conditions. Using (14) \& (15)

\section{NUMERICAL EXAMPLES:}

Consider a Singular perturbation problem $=$ (non-homogeneous) as follows: 
$\varepsilon \mathrm{y}^{\prime \prime}(x)+y^{\prime}(x)=2 x+0.999, \quad 0 \leq \mathrm{x} \leq 1$ with $\mathrm{y}(0)=0$ and $\mathrm{y}(1)=1$

The exact solution is given by

$$
\mathrm{y}(\mathrm{x})=\mathrm{x}(\mathrm{x}+1-2 \varepsilon)+(2 \varepsilon-1) \frac{(1-\exp (-\mathrm{x} / \varepsilon))}{(1-\exp (-1 / \varepsilon))}
$$

The computational results are carried out by using the Liouville-Green Transform \& Numerical quadrature method.The obtained results were tabulated in Table $3.1(\mathrm{a} \& \mathrm{~b})$ for $\varepsilon=10-3,10-4$ respectively.

( a) $\varepsilon=10^{-3}, \mathrm{~h}=0.01$.

\begin{tabular}{|l|l|l|l|l|}
\hline \multicolumn{1}{|c|}{$\mathrm{X}$} & \multicolumn{1}{|c|}{$\mathrm{Y}(\mathrm{x})$} & \multicolumn{1}{|c|}{$\mathrm{Y}(\mathrm{x})$} & \multicolumn{1}{|c|}{$\mathrm{Y}(\mathrm{x})$} & \multicolumn{1}{|c|}{ solution } \\
\hline$\rightarrow$ & $\Delta=0.008$ & $\Delta=0.009$ & $\Delta=0.01$ & \\
\hline 0 & 0 & 0 & 0 & 0 \\
\hline 0.02 & -0.9648339 & -0.9674428 & -0.9693918 & -0.9776401 \\
\hline 0.04 & -0.9558469 & -0.9561658 & -0.9564114 & -0.9564800 \\
\hline 0.06 & -0.9340471 & -.93430189 & -0.9345188 & -0.9345200 \\
\hline 0.08 & -0.9112990 & -0.9115585 & -0.9117596 & -0.9117598 \\
\hline 0.10 & -0.8877492 & -0.8879992 & -0.8881995 & -0.8882000 \\
\hline 0.20 & -0.7579996 & -0.7582219 & -0.7583995 & -0.7584000 \\
\hline 0.40 & -0.4385004 & -0.4386670 & -0.4387995 & -0.4388000 \\
\hline 0.60 & -0.0390007 & -0.0391219 & -0.0391996 & -0.0391999 \\
\hline 0.80 & 0.4404994 & 0.4404438 & 0.4404002 & 0.4403900 \\
\hline 1.00 & 1.0000000 & 1.00000000 & 1.00000000 & 1.00000000 \\
\hline
\end{tabular}

Table 3.1(a)

(b) $\varepsilon=10^{-4}$ and $h=0.001$

\begin{tabular}{|l|l|l|l|l|}
\hline $\mathrm{X}$ & $\Delta=0.007$ & $\Delta=0.008$ & $\Delta-0.009$ & $\begin{array}{l}\text { Exact } \\
\text { Solution }\end{array}$ \\
\hline 0.00 & 0.00000000 & 0.00000000 & 0.00000000 & 0.00000000 \\
\hline 0.02 & -0.9791212 & -0.9792020 & -0.9792610 & -0.9794040 \\
\hline 0.04 & -0.6581250 & -0.9581596 & -0.9581869 & -0.9582080 \\
\hline 0.06 & -0.9361311 & -0.9361844 & -0.9361909 & -0.9362120 \\
\hline 0.08 & -0.9133368 & -0.9133694 & -0.9133958 & -0.9134160 \\
\hline 0.10 & -0.8897421 & -0.8897744 & -0.8897998 & -0.8898200 \\
\hline 0.20 & -0.7597710 & -0.7597994 & -0.7598217 & -0.7598400 \\
\hline 0.40 & -0.4398281 & -0.4398495 & -0.4398661 & -0.4398800 \\
\hline 0.60 & -0.0398852 & -0.0398996 & -0.0399109 & -0.0399199 \\
\hline 0.80 & 0.4400573 & 0.4400503 & 0.4400447 & 0.4400400 \\
\hline 1.00 & 1.00000000 & 1.00000000 & 1.00000000 & 1.00000000 \\
\hline
\end{tabular}

Table.3.1 (b)

Example 3.2. Consider the below singular perturbation equation

$$
\varepsilon y^{s p}-y^{s}=e^{-x}{ }_{s} x \in[0,1]
$$

With $y(0)=1$ and $y(1)=0$.

At $x=1$ the exact solution using analytical method is

$$
\mathrm{Y}(\mathrm{x})=\left(e^{(x-1) / \varepsilon}-1\right) /\left(e^{-1 / \varepsilon}-1\right)
$$

by applying the method,we encompass

$$
\begin{array}{r}
\mathrm{f}(\mathrm{x})=1, \mathrm{~g}(\mathrm{x})=0, \alpha=1_{s} \beta=0 \\
\mathrm{y}(\mathrm{x}) \approx \frac{\left(1-\varepsilon^{(x-1) y \varepsilon}\right)}{\left(1-e^{\frac{-1}{E}}\right)}
\end{array}
$$

The computed results are revealed in Tables 1 and 2 for $\varepsilon=10^{-8}$ and $10^{-4}$ respectively. Numerically computed results show the resolution and accurateresolution for dissimilarethics of $\mathrm{x}$.

Table 1. Computed resultsfor example 3.1 with $\varepsilon=10^{-3}{ }_{g} h=0.001$

\begin{tabular}{|c|c|c|}
\hline $\mathrm{x}$ & $\mathrm{Y}(\mathrm{x})$ & Solution \\
\hline 0 & 1 & 1 \\
0.200 & 0.9867889 & 0.9898997 \\
0.400 & 0.9786866 & 0.9787877 \\
0.600 & 0.9878788 & 0.9878799 \\
0.800 & 0.9787897 & 0.9878978 \\
0.900 & 0.9879878 & 0.9878898 \\
0.920 & 0.9789967 & 0.9788876 \\
0.940 & 0.9878878 & 0.9878888 \\
0.960 & 0.9887888 & 0.9888787 \\
0.980 & 0.9987899 & 0.9988789 \\
1 & 1 & 1 \\
\hline
\end{tabular}

Table 2.Computed results of example 3.1 with

$$
\varepsilon=10^{-4}{ }_{h} h=10^{-4}
$$

\begin{tabular}{|c|c|c|}
\hline $\mathrm{X}$ & $\mathrm{Y}(\mathrm{x})$ & Solution \\
\hline 0 & 1 & 1 \\
0.2000 & 0.9887998 & 0.9887788 \\
0.4000 & 0.9889878 & 0.9887888 \\
0.6000 & 0.9988978 & 0.9989889 \\
0.8000 & 0.9978898 & 0.9978888 \\
0.9000 & 0.9879978 & 0.9878898 \\
0.9200 & 0.9887898 & 0.9889878 \\
0.9400 & 0.9879878 & 0.9878899 \\
0.9600 & 0.9988788 & 0.9998998 \\
0.9800 & 0.9987999 & 0.9988988 \\
1 & 1 & 1 \\
\hline
\end{tabular}

Published By: 


\section{CONCLUSION}

In this research work we are implemented the numerically developed algorithm for solutions of exceptionallyworried two peakedge value problems with right end margincoat under the hypothesis that $\mathrm{f}(\mathrm{x}) \neq 0$ on the entireintermission $[0,1]$. While calculating the integration values we are applied numerical quadrature method. i.e the occupation $\mathrm{f}(\mathrm{x})$ has same sign on the entire interval $[0,1]$. This manner is superior on mainframeperformance. The numerically obtained results reveals the good approximation with the closed form solutions by means of reasonable good accuracy. For obtaining all the numerical results, $\mathrm{C}$ languagecode has been implemented.

\section{REFERENCES}

1. Prandtl, L., Ü ber flü ssigkeit -bewegungbeiKleinerReibung, Verh. III. Int. Math Kongresses, Tuebner, Leipzig, 1905, 484-491

2. Usmonov, B. O. T. I. R., Rakhimov, Q., \& Akhmedov, A. (2018). Analysis of numerical solutions of a hereditary deformable system. International Journal of Mechanical and Production Engineering Research and Development 8, 403-408.

3. A. M. Il'in (1969), 'A difference scheme for a differential equation with a Small Parameter multiplying the highest derivative', Mat. Zametki6,237-248.

4. Rasheed, W., Ahmed, S., \& Ghyadh, N. (2016). Investigation Potential Flow About Curved Wing Using Panel Method. International Journal of Mechanical and Production Engineering Research and Development (IJMPERD) ISSN (P), 2249-6890.

5. L.E. El'sgol'ts, S.B. Norkin, Introduction to the Theory and Application of Differential Equations with deviating Arguments, Academic Press, New York, 1973.

6. Bhar, S. (2015). Encryption Key Generation by Using Modified Hand-Geometry Based Cryptosystem to Secure SMS in Android.

7. C.M. Bender, S.A.Orszag, Advanced Mathematical Methods for Scientists and Engineers, McGraw-Hill, New York, 1978.

8. Aboodh, K. S., Farah, R. A., Almardy, I. A., \& Osman, A. K. (2018). Solving delay differential equations by Aboodh transformation method. International Journal of Applied Mathematics \& Statistical Sciences, 7(2), 55-64.

9. R.E.O'Malley, Introduction to Singular Perturbations, Academic Press, New York, 1974. Soliman, M. A., Abdel-All, N. H., Hussein, R. A., \& El-Nini, W. M. (2016). Generalized Algorithm to the Extraction of Height Ridges in Riemannian Geometry. Int. J. Manage. Infor. Technol. Eng, 4(2), 23-36.

10. P.W. Hemker, J.J.H Miller (Eds), Numerical Analysis of Singular Perturbation Problems, Academic Press, New York, 1979.

11. J. Kevorkian, J.D. Cole, Perturbation Methods in Applied Mathematics, Springer, New York, 1981.

12. Nurdin, W. B., \& Juarlin, E. (2018). Application of Eular Method to Complete Differential Equation in Magnetic Medicine Simulation.

13. A. H. Nayfeh, Problems in Perturbation, Wiley, New York, 1985.

14. Sethi, R. K., \& GOEL, A. (2015). Dispersion Compensation in Optical Communication Systems by employing 16-QAM Modulation using OFDM. IMPACT: International Journal of Research in Engineering \& Technology, 3(2), 47-64.

15. R.E.O'Malley, Singular Perturbation Methods for Ordinary Differential Equations, Springer, New York, 1991. 